\title{
A case report of immunosuppression-related Kaposi's sarcoma after autologous stem cell transplantation
}

\author{
Bert Heyrman ${ }^{*}$ (D, Ann De Becker and Rik Schots
}

\begin{abstract}
Background: Kaposi's sarcoma (KS) is a tumor formed by angioproliferations driven by Human herpes virus 8 also known as Kaposi's sarcoma-associated herpes virus (KSHV). It is best known as an acquired immune deficiency syndrome (AIDS) defining illness that may be fatal. There are only a few reports of KS after hematopoietic cell transplantation (HCT). This is the first case describing the disappearance of KS with immune recovery after autologous HCT.

Case presentation: We present the case of a 61-year-old male heterosexual patient of Moroccan origin treated for primary mediastinal non-Hodgkin lymphoma. Because of refractory disease he received multiple lines of chemotherapy prior to autologous HCT. After the second course of low-dose bis-chloroethylnitrosourea, etoposide, cytarabine, melphalan (BEAM) the patient developed several round blue skin lesions. A biopsy was performed, showing many small vessels and positive immune histochemical staining for Human herpes virus 8 (HHV-8), confirming diagnosis of KS. Human immunodeficiency virus testing was negative and work-up showed that there were no visceral lesions. When KS are limited to the skin, prognosis is usually better. The extensive chemotherapy resulted in an important immunosuppression; on day 105 after autologous HCT CD4 ${ }^{+}$count was $82 / \mathrm{mm}^{3}$. Since KS were limited to the skin and attributed to severe immune suppression a watchful waiting strategy was adopted even though in the first months after autologous HCT new skin lesions appeared. With immune recovery $\left(C D 4^{+}\right.$count $\left.>200 / \mathrm{mm}^{3}\right) 277$ days after transplant, skin lesions faded.
\end{abstract}

Conclusion: Kaposi's sarcoma remains a rare tumor that should be thought of in any patient whose immunity is down. If immune recovery is expected and disease is limited to the skin, a watchful waiting strategy can be more rewarding than intensive chemotherapy.

Keywords: Kaposi's sarcoma, Autologous stem cell transplantation

\section{Background}

Kaposi's sarcoma (KS) is a tumor characterized by mucocutaneous and visceral angioproliferations, first described by Moritz Kaposi in 1872 [1]. Today four clinical variants of KS are known [1] with similar histologic findings but different sites of involvement and rates of progression. Classic Kaposi's sarcoma, primarily found in Eastern European and Mediterranean men (male to female ratio 15:1) is mostly limited to the skin of hands and feet and follows an indolent course. Endemic KS

*Correspondence: bert.heyrman@uzbrussel.be

Department of Clinical Hematology, UZ Brussel-VUB, Laarbeeklaan 101 1090 Jette-Brussels, Belgium occurs in Africa independent of Human immunodeficiency virus (HIV) infection. In children progression is fulminant and outcome fatal whereas in adults presentation is similar to classic KS. Immunosuppression- or transplantation-associated KS occurs in organ-transplant recipients and patients receiving immunosuppressive therapy for other medical conditions. This type tends to be aggressive, involving lymph nodes, mucosa and visceral organs, sometimes in the absence of skin lesions. Epidemic or acquired immune deficiency syndrome (AIDS) associated Kaposi sarcoma is the best known variant and is commonly known to be an AIDS defining 
illness in HIV patients. It is feared for its aggressive and frequently fatal outcome.

Only 13 cases of KS after hematopoietic cell transplantation (HCT) have been described: 11 after allogeneic and two after autologous HCT [2-14]. The disease was lethal in 3/11 allogeneic and $1 / 2$ autologous HCT. In adults, skin only was the dominant clinical presentation. All three pediatric cases had visceral involvement, resulting in two fatalities (after either allogeneic or autologous HCT). The two cases described after autologous HCT had visceral involvement. The adult case, while in complete remission for his hematological malignancy, died due to disseminated KS. The pediatric case responded to recombinant alpha-interferon.

The driving agent for the proliferative growth is Kaposi's sarcoma-associated herpes virus (KSHV) also known as Human herpes virus 8 (HHV-8), a group 1 carcinogenic agent according to the International Agency for Research on Cancer [15]. Apart from KS, HHV-8 is the underlying cause of lymphoproliferative disorders such as primary effusion lymphoma [16] and multicentric Castleman disease [17]. Seroprevalence rates are low in Western countries and higher in certain geographic areas (the Mediterranean area and Africa) [18, 19]. Human herpes virus 8 prevalence is high in men with homosexual activity, apart from HIV infection and in migrants from endemic regions [17]. Saliva is believed to be the major transmission vehicle for horizontal transmission [20, 21].

Genes encoded by KSHV can induce cellular proliferation and prevent apoptosis causing a transformative effect on endothelial cells. In transplant recipients nonmalignant pathologic events as cytopenias and acute hepatitis syndromes can be provoked by KSHV [22]. One study however, conducted to investigate HHV-8 seroprevalence after allogeneic bone marrow transplantation (BMT) did not find any association between presence of antibodies directed against HHV-8 latent nuclear antigen before or after transplantation, chronic graft versus host disease, or overall BMT survival [23]. More data are needed to support this finding.

In general the level of immunosuppression and the extent of disease determine the course of KS. Visceral KS is characterized by rapid spread and risk of major bleeding with often fatal outcome. Skin limited KS typically follows an indolent course [24] and is more an aesthetic problem lowering self-esteem of HIV patients. In solid organ transplant patients 1 year survival rate is at $90 \%$ for cutaneous disease and $70 \%$ for visceral forms [25].

Immune recovery is generally defined as a rise in $\mathrm{CD}_{4}^{+}$ count above $200 / \mathrm{mm}^{3}$ and was described to be associated with a gradual disappearance of KS in HIV patients $[26,27]$. Since the introduction of HAART as a successful HIV treatment resulting in less prolonged immune deficiency, the incidence of KS has decreased substantially $[28,29]$.

Treatment intent and strategy differ depending on location and spread of disease. Tapering of dose in patients receiving immunosuppressive medication is an option. In disease limited to skin only, surgical excision or electrochemotherapy is the most preferable approach, radiotherapy appears to be abandoned due to local side effects (edema and ulcerations) [22]. In solid organ transplant patients intensive therapy is required in case of persistent functional disability or life-threatening disease [30]. Possible options are the use of interferon-alpha or chemotherapy using doxorubicin in monotherapy or vincristine, etoposide and bleomycin in monotherapy or in combination with anthracyclines [31]. The use of antiviral treatment (cidofovir, foscarnet, ganciclovir or valganciclovir) is considered without benefit [32, 33]. Since neoplastic KS spindle cells harbor a latent HHV-8 infection eradication is not possible [34-36]. One could start antiviral therapy in cases of aggressive disseminated KS with high HHV-8 viremia, aiming to at least resolve cytopenias. Novel targeted therapies are currently under investigation. Imatinib a tyrosine kinase inhibitor of c-Kit, expressed by KS tumor cells, showed promising results in a phase 2 study conducted in AIDS-related KS patients [37].

Here we report the rise and fall of Kaposi sarcoma of the skin coinciding with immunosuppression and reconstitution after autologous HCT in a 61-year-old patient of Moroccan origin treated for primary mediastinal nonHodgkin lymphoma.

\section{Case presentation}

\section{Case history}

A 61-year-old heterosexual male of Moroccan origin was diagnosed with primary mediastinal non-Hodgkin lymphoma. Other than hypertension treated with amlodipine he had no medical history. Viral serology prior to starting therapy showed previous hepatitis B infection, HIV screening was negative.

The patient was refractory to rituximab, cyclophosphamide, doxorubicin, vincristine and prednisone (R-CHOP). Second line therapy with rituximab, dexamethasone, cytarabine and cisplatin (R-DHAP) had to be abandoned after one cycle because of invalidating tinnitus. Rituximab, ifosfamide, carboplatin and etoposide (R-ICE) was started with an increase in tumor activity and volume on positron emission tomography (PET)/ computed tomography (CT) after the first cycle. In August 2013 the patient was hospitalized for high dose cyclophosphamide for stem cell mobilization. Treatment continued with low-dose BEAM (bis-chloroethylnitrosourea $60 \mathrm{mg} / \mathrm{m}^{2}$ on day 1 , etoposide $15 \mathrm{mg} / \mathrm{m}^{2}$ on day 
$2,3,4$ and 5 , cytarabine $2 \times 100 \mathrm{mg} / \mathrm{m}^{2}$ on day $2,3,4$ and 5 , and melphalan $30 \mathrm{mg} / \mathrm{m}^{2}$ on day 6 ) followed by autologous stem cell rescue, resulting in a partial response. We repeated low-dose BEAM followed by stem cell infusion and obtained stable disease on PET/CT. After the second cycle we noticed blue, round lesions on the left forearm and both legs, slightly elevated and sensitive with pressure (Fig. 1). Skin biopsies were taken. Microscopy showed a normal epidermis, but the dermis showed many small vessels in clusters with swollen endothelial cells (Fig. 2). Immune-histochemical staining was positive for HHV-8 (Fig. 3) and negative for cytomegalovirus (CMV). The diagnosis of Kaposi's sarcoma of the skin was made. Serology confirmed a negative HIV status. Review of the CT scans showed no evidence of visceral sarcomas. After 1 week of ganciclovir because of a positive polymerase chain reaction (PCR) for CMV, treatment continued with full dose BEAM (bis-chloroethylnitrosourea $300 \mathrm{mg} / \mathrm{m}^{2}$ on day 1 , etoposide $200 \mathrm{mg} / \mathrm{m}^{2}$ day $2-5$, cytarabine $2 \times 200 \mathrm{mg} / \mathrm{m}^{2}$ day $2-5$, and melphalan $140 \mathrm{mg} /$ $\mathrm{m}^{2}$ day 6) and autologous stem cell transplantation. During hospitalization no new skin lesions appeared.

Two months later more skin lesions appeared on the lower legs. PET/CT at that moment showed a fibrotic lesion in the anterior mediastinum with volume decrease and complete resolution of metabolic activity. The patient was consolidated with 40 Gy radiotherapy. During this treatment additional lesions appeared on the lower legs, his general condition was cumbersome. A new biopsy confirmed the previous diagnosis of Kaposi's sarcoma. $\mathrm{CD}^{+}{ }^{+}$count at that time, 3 months after the last HCT was at $82 / \mathrm{mm}^{3}$. Later, the spreading of KS stopped and on day 182 after HCT CD4 $4^{+}$count rose to $156 / \mathrm{mm}^{3}$.

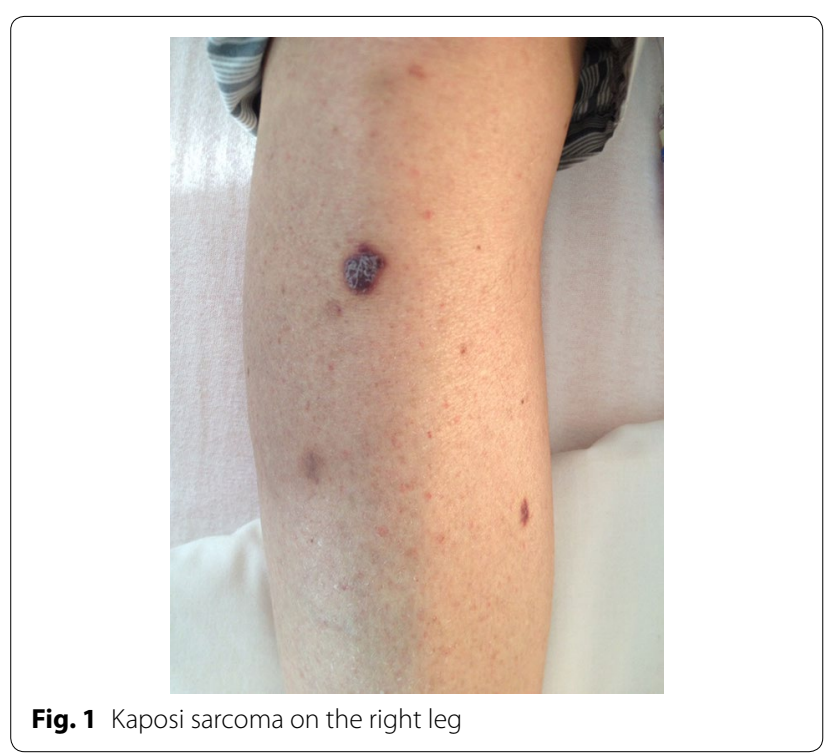

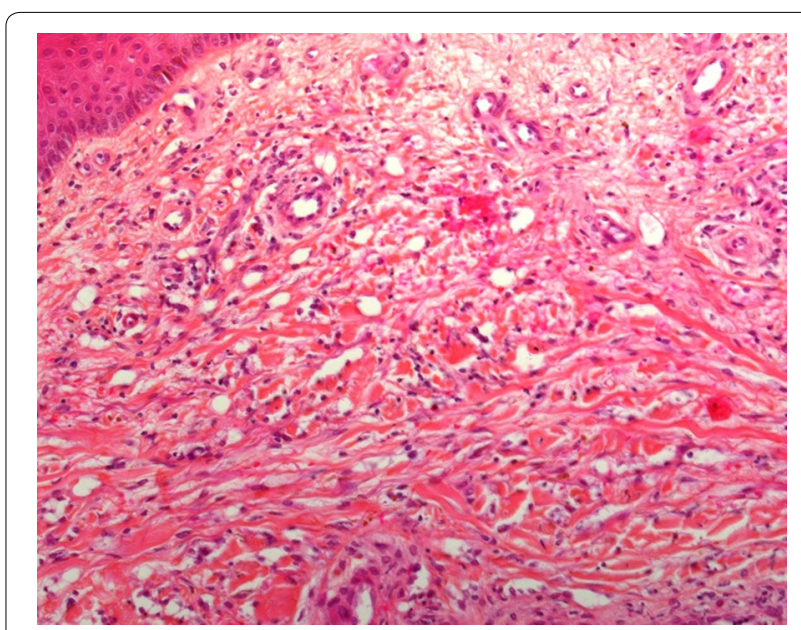

Fig. 2 Endothelial swelling [Skin biopsy, HES (hematoxylin, eosin, saffran) routine staining, $200 \times$ ]

Nine months after transplantation, counting 227 $\mathrm{CD}^{+} / \mathrm{mm}^{3}$ in peripheral blood, skin lesions gradually disappeared (Fig. 4). A new CT scan confirmed complete response status of the lymphoma.

\section{Discussion}

In this case study we report a patient with dermal Kaposi's sarcomas associated with HHV-8 appearing shortly after autologous stem cell transplantation. Spread was limited to the skin; initially the left forearm and lower legs, later some abdominal skin lesions appeared. HHV-8 serology prior to transplantation was not known and not a routine examination in our center. With a negative history in male sexual contact, we consider our patient from Moroccan origin to be an endemic carrier.

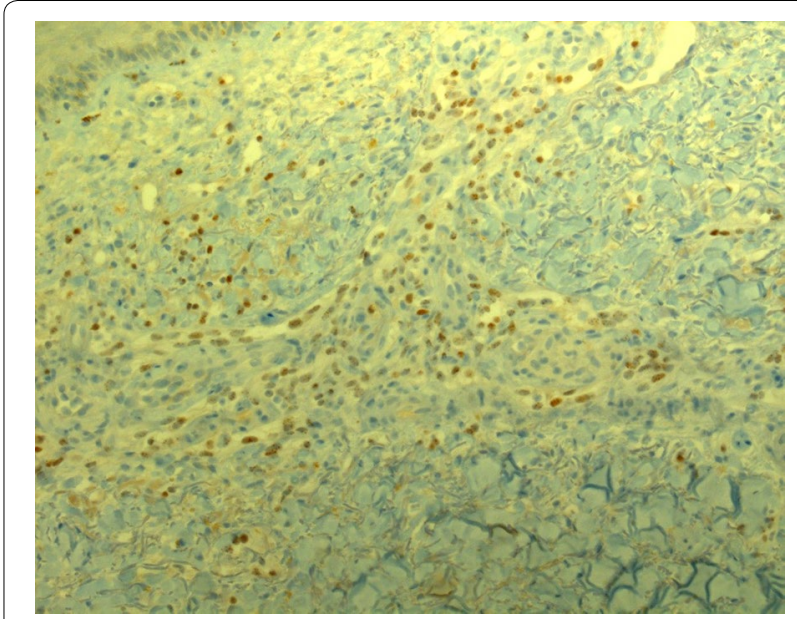

Fig. 3 HHV-8 positivity (Skin biopsy, immune histochemical staining HHV $-8,200 \times)$ 


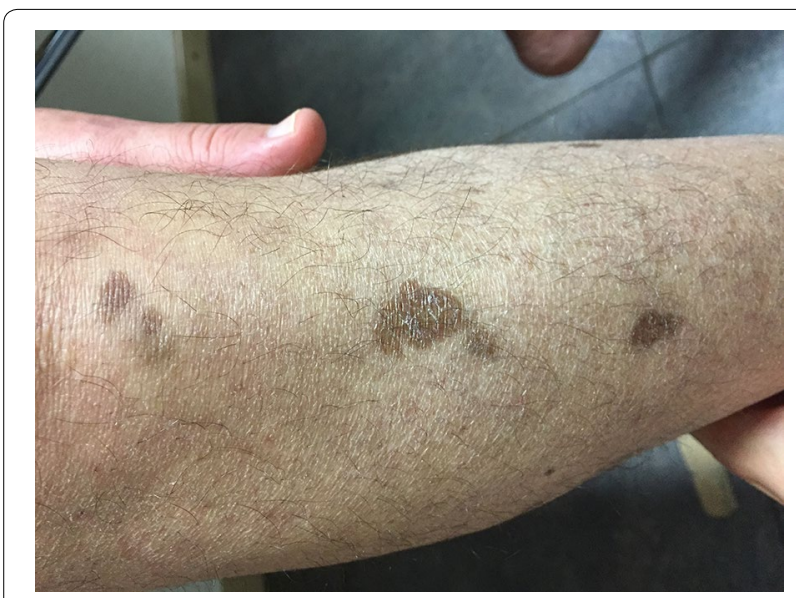

Fig. 4 Fading of Kaposi sarcoma on the right leg

Several lines of intensive chemotherapy followed by autologous HCT is considered an aggressive form of immune suppression, without immune suppressive therapy in relation to transplant. The patient's immune deficient state was confirmed by a low $\mathrm{CD} 4^{+}$count of $82 / \mathrm{mm}^{3} 105$ days after the last HCT. On day $182 \mathrm{CD}^{+}$ count rose to $156 / \mathrm{mm}^{3}$ and to $227 / \mathrm{mm}^{3}$ on day 277 after HCT, coinciding with a remarkable decrease in skin lesions. This observation supports that $\mathrm{KS}$ in this case was related to a low $\mathrm{CD}^{+}$count and not a case of classic KS.

In our case there was only limited disease of the skin without aesthetic concern. We focused on the initial disease for further treatment, as this was considered an intense treatment option for KS as well. However intense chemotherapy using full dose BEAM did not ameliorate his original lesions. When new KS were formed, we decided to watch and wait for immune recovery. It was not until $\mathrm{CD}^{+}$count rose to $227 / \mathrm{mm}^{3}$ that the lesions clearly faded.

\section{Conclusions}

This is the third case of appearance of KS and the first describing resolution of Kaposi's sarcoma with $\mathrm{CD}^{+}$ cell recovery after autologous HCT. Kaposi's sarcoma remains a rare tumor that should be thought of in any patient whose immunity is down. If immune recovery is expected and disease is limited to the skin, a watchful waiting strategy can be more rewarding than intensive chemotherapy.

\section{Consent}

Written informed consent was obtained from the patient for publication of this case report and any accompanying images.

\section{Abbreviations}

KS: Kaposi's sarcoma; HHV-8: human herpes virus 8; HCT: hematopoietic cell transplantation; CMV: cytomegalovirus; HIV: human immunodeficiency virus; AIDS: acquired immune deficiency syndrome; PET: positron emission tomography; CT: computed tomography; R-CHOP: rituximab cyclophosphamide doxorubicin vincristine prednisone; R-DHAP: rituximab dexamethasone cytarabine cisplatin; R-ICE: rituximab ifosfamide carboplatin etoposide; BEAM: bis-chloroethylnitrosourea etoposide cytosar melphalan.

\section{Authors' contributions}

$\mathrm{BH}$ literature review and drafting the manuscript. ADB critically revising and drafting the manuscript. RS Critically revising and drafting the manuscript. All authors read and approved the final the manuscript.

\section{Acknowledgements}

Karel Fostier for follow up of the patient and obtaining informed consent Annieta Goossens for the microscopy pictures. All authors are full-time employed in UZ Brussel. No specific funding was granted for drafting of this manuscript.

\section{Competing interests}

The authors declare that they have no competing interests.

Received: 16 November 2015 Accepted: 15 March 2016

Published online: 24 March 2016

\section{References}

1. Antman K, Chang Y. Kaposi's sarcoma. N Engl J Med. 2000;342:1027-38.

2. Bruno B, Sorasio R, Barozzi P, Vieira J, Omede P, Giaretta F, et al. Kaposi's sarcoma triggered by endogenous HHV-8 reactivation after non myeloablative allogeneic haematopoietic transplantation. Eur J Haematol. 2006;76(4):342-7.

3. Porta F, Bongiorno M, Locatelli F, Gibardi A, Lanfranchi A, Rosso R, et al. Kaposi's sarcoma in a child after autologous bone marrow transplantation for non-Hodgkin's lymphoma. Cancer. 1991;68(6):1361-4.

4. Helg C, Adatto M, Salomon D, Roux E, Miralbell R, Chapuis B, et al. Kaposi's sarcoma following allogeneic bone marrow transplantation. Bone Marrow Transplant. 1994;14(6):999-1001.

5. Gluckman E, Parquet N, Scieux C, Deplanche M, Traineau R, Betheau P, et al. KS-associated herpesvirus-like DNA sequences after allogeneic bone-marrow transplantation. Lancet. 1995;346(8989):1558-9.

6. Erer B, Angelucci E, Muretto P, Ripalti M, Rapa S, Gaziev D, et al. Kaposi's sarcoma after allogeneic bone marrow transplantation. Bone Marrow Transplant. 1997;19(6):629-31.

7. Vivancos P, Sarre J, Palou J, Valls A, Garcia J, Granena A. Kaposi's sarcoma after autologous bone marrow transplantation for multiple myeloma. Bone Marrow Transplant. 1997;17(4):669-71.

8. Tamariz-Martel R, Maldonado MS, Carrillo R, Crespo D, Perez-Caballero C, Munoz A. Kaposi's sarcoma after allogeneic bone marrow transplantation in a child. Haematologica. 2000;85(8):884-5.

9. de Medeiros BC, Rezuke WN, Ricci A Jr, Tsongalis G, Shen PU, Bona RD, et al. Kaposi's sarcoma following allogeneic hematopoietic stem cell transplantation for chronic myelogenous leukemia. Acta Haematol. 2000;104(2):115-8.

10. Palencia SI, Rodriguez-Peralto JL, Catastano E, de la Serna J, Vanaclocha F, Iglesias-Diez L. Kaposi's sarcoma after allogeneic peripheral blood stem cell transplantation. Int J Dermatol. 2003;42(8):647-9.

11. Sala I, Faraci M, Magnano GM, Sementa A, di Marco E, Garaventa A, et al. HHV-8-related visceral Kaposi's sarcoma following allogeneic HSCT: report of a pediatric case and literature review. Pediatr Transplant. 2011;15(1):E8-11.

12. Abbas AA, Jastaniah WA. Extensive gingival and respiratory tract Kaposi sarcoma in a child after allogeneic hematopoietic stem cell transplantation. J Pediatr Hematol Oncol. 2012;34(2):E53-5.

13. Deauna-Limayo D, Rajabi B, Qui W, Sweetenham J. Kaposi sarcoma after non-myeloablative hematopoietic stem cell transplant: response to withdrawal of immunosuppressant therapy correlated with whole blood 
human herpesvirus-8 reverse transcriptase-polymerase chain reaction levels. Leukemia Lymphoma. 2013;54(10):2299-302.

14. Avivi I, Fineman R, Haddad N, Katz T, Oren I, Rowe JM. Fatal Kaposi sarcoma after allogeneic stem cell transplant. Leukemia Lymphoma. 2011;52(12):2402-4

15. IARC Monographs on the Evaluation of Carcinogenic Risks to Humans: Biological Agents, Volume 100 B, A Review of Human Carcinogen. Lyon, France: International Agency for Research on Cancer; 2012.

16. Cesarman E, Chamg Y, Moore PS, Said JW, Knowles DM. Kaposi's sarcomaassociated herpesvirus-like DNA sequences in AIDS-related body-cavitybased lymphomas. N Eng J Med. 1995;332:1186-91.

17. Soulier J, Grollet L, Oksenhendler E, Cacoub P, Cazals-Hatem D, Babinet P. Kaposi's sarcoma-associated herpesvirus-like DNA sequences in multicentric Castleman's disease. Blood. 1995;86:1276-80.

18. Jenkins FJ, Hofman LJ, Liegey-Dougall A. Reactivation of and primary infection with human herpesvirus 8 among solid-organ transplant recipients. J Infect Dis. 2002;185(9):1238-43.

19. Moor PS. The emergence of Kaposi's sarcoma-associated herpesvirus (human herpesvirus 8). N Engl J Med. 2000;343:1411-3.

20. UldrickTS, Whitby D. Update on KSHV epidemiology, Kaposi sarcoma pathogenesis, and treatment of Kaposi sarcoma. Cancer Lett. 2011;305:150-62.

21. Blackbourn DJ, Lennette ET, Ambroziak J, Mourich DV, Levy JA. Human herpesvirus 8 detection in nasal secretions and saliva. J Infect Dis. 1998;177:213-6.

22. Riva G, Luppi M, Barozzi P, Forghieri F, Potenza L. How I treat HHV-8/KSHVrelated diseases in posttransplant patients. Blood. 2012;120:4150-9.

23. Rozenzwajg M, Fery N, Bons V, Damaj G, Gluckman E, Gluckman J. Human herpesvirus 8 (HHV-8) serology in allogeneic bone marrow transplant recipients. Bone Marrow Transplant. 1999;24:351-4.

24. Akasbi Y, Awasa A, Arifi S, Mellas N, El Mesbahi O. Non-HIV Kaposi's sarcoma: a review and therapeutic perspectives. Bull Cancer. 2012;99:E92-9.

25. Woodle ES, Hanaway M, Buell J, Gross T, First MR, Trofe J, et al. Kaposi's sarcoma: an analysis of the US and international experiences from the Israel Penn International Transplant Tumor Registry. Transplant Proc 2001;33:3660-36611.
26. Gazzola L, Tincati C, Bellistri GM, et al. The absence of CD4 ${ }^{+} \mathrm{T}$ cell count recovery despite receipt of virologically suppressive highly active antiretroviral therapy: clinical risk, immunological gaps, and therapeutic options. Clin Infect Dis. 2009;48(3):328-37.

27. Stebbing J, Portsmouth S, Gazzard B. How does HAART lead to the resolution of Kaposi's sarcoma? J Antimicrob Chemother. 2003;51:1095-8.

28. Portsmouth S, Stebbing J, Gill J, et al. A comparison of regimens based on non-nucleoside reverse transcriptase inhibitors or protease inhibitors in preventing Kaposi's sarcoma. AIDS. 2003;17:17-22.

29. Bower M, Fox P, Fife K, et al. Highly active anti-retroviral therapy (HAART) prolongs time to treatment failure in Kaposi's sarcoma. AIDS. 1999;13:2105-11.

30. Barete S, Calvez V, Mouquet C, Barrou B, Kreis H, Dantal J. Clinical features and contribution of virological findings to the management of Kaposi Sarcoma in organ-allograft recipients. Arch Dermatol. 2000;136:1452-8.

31. Shepherd FA, Maher E, Cardella C, Cole E, Greig P, Wade JA, et al. Treatment of Kaposi's sarcoma after solid organ transplantation. J Clin Oncol. 1997;15:2371-7.

32. Kedes DH, Ganem D. Sensitivity of Kaposi's sarcoma-associated herpesvirus replication to antiviral drugs. Implications for potential therapy. J Clin Invest. 1997;99(9):2082-6.

33. Casper C, Krantz EM, Corey L, Kuntw CR, Wang J, Selke S, et al. Valganciclovir for suppression of human herpesvirus-8 replication: a randomized, double-blind, placebo-controlled, crossover trial. J Infect Dis. 2008;198(1):23-30.

34. Riva G, Barozzi P, Torelli G, Luppi M. Immunological and inflammatory features of Kaposi's sarcoma and other Kaposi's sarcoma-associated herpesvirus/human herpesvirus 8-associated neoplasias. AIDS Rev. 2010;12(1):40-51.

35. Schulz TF. The pleiotropic effects of Kaposi's sarcoma herpesvirus. J Pathol. 2006;208(2):187-98.

36. Ariza-Heredia EJ, Razonable RR. Human herpes virus 8 in solid organ transplantation. Transplantation. 2011;92(8):837-44.

37. Koon HB, Krown SE, Lee JY, Honda K, Rapisuwon S, Wang Z, et al. Phase II trial of imatinib in AIDS-associated Kaposi's sarcoma: AIDS Malignancy Consortium Protocol 042. J Clin Oncol. 2014;32(5):402-8.

\section{Submit your next manuscript to BioMed Central and we will help you at every step:}

- We accept pre-submission inquiries

- Our selector tool helps you to find the most relevant journal

- We provide round the clock customer support

- Convenient online submission

- Thorough peer review

- Inclusion in PubMed and all major indexing services

- Maximum visibility for your research

Submit your manuscript at www.biomedcentral.com/submit
() Biomed Central 